\title{
Effect of rhizosphere inoculation with Bacillus strains and phytopathogens on the contents of volatiles and human health-related compounds in tomato fruits
}

\author{
María Fernanda RUIZ-CISNEROS ${ }^{1}$, José de Jesús ORNELAS-PAZ1, Guadalupe Isela OLIVAS-OROZCO르, \\ Carlos Horacio ACOSTA-MUÑIZ ${ }^{1}$, Miguel Ángel SALAS-MARINA ${ }^{2}$, Francisco Javier MOLINA-CORRAL ${ }^{1}$, \\ David Ignacio BERLANGA-REYES ${ }^{1}$, Sylvia Patricia Fernández-PAVÍA33, Octavio Jhonathan CAMBERO-CAMPOS ${ }^{4}$, \\ Claudio RIOS-VELASCO ${ }^{1 *}$ (D)
}

\begin{abstract}
This study consisted of determining the effect of Bacillus strains inoculated alone or in combination with phytopathogenic fungi on the production of human health-related compounds and volatile organic compounds (VOCs) in tomato fruits. Seedlings were cultivated under greenhouse conditions and inoculated with B. amyloliquefaciens, B. methylotrophicus and B. subtilis alone or in combination with Alternaria solani, Fusarium oxysporum and Phytophthora infestans. Fully ripe fruits were harvested and evaluated for carotenoid, phenol and VOCs contents. Lycopene was the most abundant carotenoid (46.4-167.62 $\mu \mathrm{g} / \mathrm{g})$, followed by $\beta$-carotene and lutein. Fruits from plants inoculated with Bacillus had the highest carotenoid content. In contrast, phytopathogens decreased the carotenoid contents, especially the lycopene content. The content of total phenols ranged from 0.42 to $0.90 \mathrm{mg} \mathrm{GAE} / \mathrm{g}$. The content of these compounds increased 1.5-fold in fruits from plants inoculated with Bacillus strains, especially those treated with B. methylotrophicus, but the greatest increase (1.9-fold) was observed in plants inoculated with phytopathogens. Both Bacillus strains and pathogens increased the antioxidant capacity, with a 2.8 -fold increase compared to the control. Thirty-two VOCs were identified in the tested tomatoes. The Bacillus strains caused an increase in the concentration of VOCs, which could be associated with an increase in fruit quality.
\end{abstract}

Keywords: biocontrol agents; plant growth-promoting rhizobacteria; nutritional value; flavor; quality.

Practical Application: This study shows the ability of Bacillus strains to increase human health-related compounds and VOCs in tomato fruits, which could expand their use in fruit and vegetable crops.

\section{Introduction}

Tomato (Solanum lycopersicon L., Solanales: Solanaceae) is a highly consumed fruit worldwide. Tomato quality is determined by several attributes, including color, nutritional value and flavor (Vogel et al., 2010) and is highly dependent on cultivar (Vieira et al., 2019), climatic conditions and the production system used. Tomatoes are rich in human health-related compounds, especially carotenoids and phenols, which greatly contribute to their well-known antioxidant capacity (Ligor et al., 2014; Ha et al., 2015; Pellicanò et al., 2020). The beneficial effects of fresh tomato, tomato products, tomato carotenoids and phenols on the prevention of several cancer forms, cardiovascular diseases, age-related macular degeneration and other chronic diseases have been demonstrated (Zanfini et al., 2010; CervantesPaz et al., 2012; Pesaresi et al., 2014). These beneficial effects have mainly been attributed to the antioxidant capacity of tomatoes, which contributes to preventing an excess of free radicals in human cells. High levels of free radicals in cells are involved in the pathogenesis of many different diseases (Zanfini et al., 2010; Mukherjee et al., 2017). Thus, the carotenoid and phenol contents are important quality attributes of tomato fruits. On the other hand, carotenoids are also precursors of volatile compounds (VOCs) involved in the aroma of tomato fruits (El Hadi et al., 2013). The volatiles derived from carotenoids are highly biosynthesized at advanced ripening stages (López-Vidal et al., 2014; Su et al., 2015). The flavor of tomatoes is a product of the interaction of sugars, organic acids, and $\sim 400$ VOCs, with $20-30$ of them being significant contributors to tomato aroma. These VOCs are synthetized not only from carotenoids but also from lipids, amino acids, lignin, phenols and terpenes (Vogel et al., 2010; Dávila-Aviña et al., 2011). Several studies have demonstrated that the profile of human health-related compounds and VOCs in tomatoes can be affected by diverse pre- and postharvesting factors, mainly including geographic origin, environmental factors, cultivation practices, harvest time, storage conditions, genotype and ripening stage (Dávila-Aviña et al., 2011; Rambla et al., 2015). Recently, literature has demonstrated that the interaction between plants and microorganisms, either pathogenic or antagonistic, can alter the quality of tomatoes; however, little literature is available in this regard (Ordookhani et al., 2010; Ordookhani \& Zare 2011; Parewa et al., 2014), since previous 
studies have mainly focused on agronomic variables such as fruit size, yield, total soluble solids, and titratable acidity, but have not focused on the nutritional content and aroma compounds related to fruit quality. Some Bacillus strains, known as rhizobacteria, have been widely studied as biocontrol agents and have shown satisfactory results as plant growth promoters (Beneduzi et al., 2012). These microorganisms also influenced several quality attributes of tomato fruits, including the lycopene content and antioxidant capacity (Ordookhani et al., 2010). However, pathogenic microorganisms can also induce the biosynthesis of defense metabolites in plants, especially phenolic compounds (Kubalt, 2016), which might contribute to the antioxidant and protective effects of tomatoes on human health. Thus, the interaction of pathogenic and plant growth-promoting microorganisms might exert a higher effect on tomato fruit quality than the individual effect of each type of microorganism. Unfortunately, this effect has not been systematically studied. Therefore, the aim of the study was to determine the contents of human health-related compounds, such as carotenoids, total phenolics, and VOCs, and the antioxidant capacity of tomato fruits harvested from plants subjected to biotic stress by inoculation of the substrate with antagonistic Bacillus strains alone and in combination with tomato pathogenic fungi.

\section{Materials and methods}

\subsection{Chemicals}

High-performance liquid chromatography (HPLC)-grade solvents (methanol, tert-butyl methyl ether, acetone, and water) were purchased from J.T. Baker (Baker-Mallinckrodt, Mexico). Standards (purity $>95 \%$ ) of all-trans-lycopene, all-trans- $\beta$-carotene, all-trans-lutein and VOCs were purchased from Sigma-Aldrich (St. Louis, MO, USA). Culture media [Luria Bertani (LB) broth and nutritive broth] were purchased from Sigma-Aldrich (St. Louis, MO, USA). Substrates (vermiculite and peat moss) were purchased from Termolita, S.A. de C.V. (Nuevo Leon, Mexico). Fertilizers were provided by Ferti-urea, Productora de Fertilizantes del Noroeste, S.A. de C.V. (Sonora, Mexico), and poly-feed, greenhouse grade, soluble solid fertilizer NPK 1919-19 was obtained from Haifa México, S.A. de C.V. (Mexico).

\subsection{Plants, microorganisms and pollinators}

Tomato seeds (Lycopersicon esculentum Mill. cv. Merlice) were purchased from DeRuiter ${ }^{\text {rwx }}$ (Monsanto, Holland). Three strains of the Bacillus genus [B. methylotrophicus CIAD-Bm, Bm; B. amyloliquefaciens CIAD-Ba, Ba; B. subtilis subsp. inaquosorum CIAD-Bs, Bs (NCBI accession numbers: MT218327.1, MT218328.1 and MT218329.1, respectively)] and three tomato pathogenic fungi [Alternaria solani CIAD-As, As (NCBI accession number MT268968.1); Fusarium oxysporum CIAD-Fo, Fo (NCBI accession number MT268967.1; and Phytophthora infestans, $\mathrm{Pi})$ ] were tested alone or in combination. The Bacillus strains were obtained from the ceparium of the Centro de Investigacion en Alimentacion y Desarrollo A.C. (Cuauhtemoc, Chihuahua, Mexico) and Universidad Michoacana de San Nicolas de Hidalgo (Morelia, Michoacan, Mexico). The pathogenic fungi were isolated from tomato crops in Mexico. The pollinator Bombus terrestris
L. (Hymenoptera: Apidae) was purchased from Koppert Mexico S.A. de C.V. (Queretaro, México).

\subsection{Establishment of tomato crop and microorganism inoculation}

The tomato crop was established in a greenhouse in Cuauhtemoc,

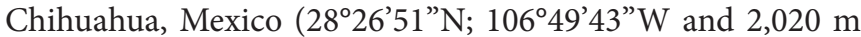
asl). The seeds were germinated and then transplanted to $6 \mathrm{~L}$ black plastic bags containing a mixture of autoclaved substrate $\left(121^{\circ} \mathrm{C}, 15 \mathrm{psi}, 1 \mathrm{~h}\right)$ composed of loamy soil:vermiculite:peat moss at a 1:1:1 ratio. Plants were fertilized with $250 \mathrm{~mL}$ of urea $(6 \mathrm{~g} / \mathrm{L})$ and Triple $19(2 \mathrm{~g} / \mathrm{L})$ and $10 \mathrm{~mL}$ of Murashige and Skoog medium $(4.4 \mathrm{~g} / \mathrm{L})$ every 30 days after transplanting (DAT) during the production cycle. Pollination was performed by a $B$. terrestris colony.

Bacteria were grown in LB broth for $48 \mathrm{~h}$, while fungi were grown for $5 \mathrm{~d}$ in nutrient broth, except for P. infestans, which was grown on Corn Meal Agar (CMA) medium. Explants with mycelial growth of the oomycete were used to induce zoosporangia formation in a $1 \%$ sterile soil solution maintained at $5{ }^{\circ} \mathrm{C}$ for $30 \mathrm{~min}$, followed by exposure to ambient temperature to induce formation and release of zoospores.

The pathogens and/or antagonists were individually applied to the substrate of 270 seedlings at eight DAT, according to the concentrations shown in Table 1 . Thirty milliliters (4.5-6.0 $\times 10^{10} \mathrm{CFU} / \mathrm{mL}$ ) of bacterial suspension (2-d-old inoculum for Bacillus strains) and $20 \mathrm{~mL}\left(2.6-7.8 \times 10^{7}\right.$ conidia or spores $/ \mathrm{mL}$ ) of phytopathogenic fungal suspension (5-d-old inoculum) were applied. Sixty seedlings were used to monitor the effects of each antagonistic bacterium and pathogen alone, i.e., 10 for each (T2-T7, Table 1), along with 10 uninoculated seedlings used as control plants (T1, Table 1), and 90 seedlings were used for confrontation tests between antagonists and pathogens (T8-T16, Table 1). In the interaction treatments, the corresponding phytopathogen fungus was applied at 18 DAT. The levels of antagonists were maintained with three doses of inoculum at 20-day intervals. The tomato plants were evaluated during the production cycle (April to October). Tomato fruits were harvested at the red ripening stage. A composite sample of chopped tomatoes was obtained from 20 fruits per treatment and stored at $-80^{\circ} \mathrm{C}$ until VOC, carotenoid, total phenolic content (TPC) and antioxidant activity analyses.

\subsection{Carotenoid analysis}

Carotenoid extraction was performed according to CervantesPaz et al. (2012). The crude extracts of tomato fruits $(20 \mu \mathrm{L})$ were injected into an HP 1100 series HPLC system (Hewlett-Packard $\mathrm{GmbH}$, Waldbronn, Germany) equipped with a diode array detector (DAD). The UV-Vis spectra for all peaks were recorded between 200 and $600 \mathrm{~nm}$. The HPLC system was equipped with a $_{30}$ reversed-phase column $(4.6 \times 150 \mathrm{~mm}, 3 \mu \mathrm{m}$; YMC Inc., Milford, MA, USA), which was maintained at $15^{\circ} \mathrm{C}$. The mobile phase consisted of water (solvent A), methanol (solvent B), and methyl tert-butyl ether (solvent $\mathrm{C}$ ) with the following gradient program: $4 \% \mathrm{~A} / 94.5 \% \mathrm{~B} / 1.5 \% \mathrm{C}$ at $0 \mathrm{~min} ; 4 \% \mathrm{~A} / 68 \% \mathrm{~B} / 28 \%$ $\mathrm{C}$ at $31 \mathrm{~min} ; 4 \% \mathrm{~A} / 30 \% \mathrm{~B} / 66 \% \mathrm{C}$ at $83 \mathrm{~min}$; and $4 \% \mathrm{~A} / 0 \%$ 
Table 1. Treatments and concentrations (CFU or conidia/mL) of inoculations with Bacillus strains and tomato pathogenic fungi applied to tomato plants.

\begin{tabular}{|c|c|c|c|c|}
\hline \multicolumn{3}{|c|}{ Treatment } & \multirow{2}{*}{ Antagonists $(\mathrm{CFU} / \mathrm{mL})$} & \multirow{2}{*}{$\begin{array}{c}\text { Phytopathogens (conidia or } \\
\text { spores } / \mathrm{mL} \text { ) }\end{array}$} \\
\hline Code & Antagonistic bacteria & Phytopathogens & & \\
\hline $\mathrm{T} 1$ & Control & - & - & - \\
\hline $\mathrm{T} 2$ & Bacillus amyloliquefaciens (Ba) & - & $1.8 \times 10^{9}$ & - \\
\hline $\mathrm{T} 3$ & B. methylotrophicus (Bm) & - & $2.0 \times 10^{9}$ & - \\
\hline $\mathrm{T} 4$ & $\begin{array}{l}\text { B. subtilis subsp. inaquosorum } \\
\text { (Bs) }\end{array}$ & - & $1.5 \times 10^{9}$ & - \\
\hline T5 & - & Fusarium oxysporum (Fo) & - & $1.3 \times 10^{6}$ \\
\hline T6 & - & Alternaria solani (As) & - & $3.9 \times 10^{6}$ \\
\hline $\mathrm{T} 7$ & - & Phytophthora infestans $(\mathrm{Pi})$ & - & $2.6 \times 10^{6}$ \\
\hline $\mathrm{T} 8$ & $B a$ & Fo & $1.8 \times 10^{9}$ & $1.3 \times 10^{6}$ \\
\hline T9 & $B a$ & As & $1.8 \times 10^{9}$ & $3.9 \times 10^{6}$ \\
\hline $\mathrm{T} 10$ & $B a$ & $P i$ & $1.8 \times 10^{9}$ & $2.6 \times 10^{6}$ \\
\hline T11 & $B m$ & Fo & $2.0 \times 10^{9}$ & $1.3 \times 10^{6}$ \\
\hline $\mathrm{T} 12$ & $B m$ & As & $2.0 \times 10^{9}$ & $3.9 \times 10^{6}$ \\
\hline $\mathrm{T} 13$ & $B m$ & $P i$ & $2.0 \times 10^{9}$ & $2.6 \times 10^{6}$ \\
\hline T14 & $B s$ & Fo & $1.5 \times 10^{9}$ & $1.3 \times 10^{6}$ \\
\hline $\mathrm{T} 15$ & Bs & As & $1.5 \times 10^{9}$ & $3.9 \times 10^{6}$ \\
\hline T16 & Bs & $P i$ & $1.5 \times 10^{9}$ & $2.6 \times 10^{6}$ \\
\hline
\end{tabular}

$\mathrm{CFU}=$ Colony Forming Units.

$\mathrm{B} / 96 \% \mathrm{C}$, at 85 to $90 \mathrm{~min}$. The flow rate was $0.75 \mathrm{~mL} / \mathrm{min}$. The identification and quantification of carotenoids was performed using reference compounds.

\subsection{Total Phenolic Content (TPC)}

A subsample of chopped tomatoes ( $4 \mathrm{~g}$ ) was homogenized in $20 \mathrm{~mL}$ of methanol using an Ultra-Turrax T 25 homogenizer (IKA Labortechnik, Staufen, Germany). The mixture was centrifuged $\left(24,652 \times g / 20 \mathrm{~min} / 4^{\circ} \mathrm{C}\right)$, and the supernatant was recovered and used for TPC and antioxidant capacity analysis by the Folin Ciocalteu method at $750 \mathrm{~nm}$, according to Spanos et al. (1990). The concentration of phenolic compounds was expressed as $\mathrm{mg}$ of gallic acid equivalent (GAE) per gram of fruit (mg GAE/g). Each extract was evaluated four times.

\subsection{Antioxidant capacity}

The antioxidant capacity of tomato extracts was determined using the DPPH assay, according to Brand-Williams et al. (1995). A sufficient volume of DPPH was prepared $(\sim 1 \mathrm{~L})$ at a concentration of $25 \mathrm{mg} / \mathrm{L}$ in methanol. The absorbance of the mixture was adjusted to $0.7 \pm 0.02$ (value adjusted with the blank) at $515 \mathrm{~nm}$. Twenty microliters of the diluted samples were placed in the wells of the microplate, and $20 \mu \mathrm{L}$ of methanol was used instead of sample as a blank; a blank of pure methanol was also analyzed by adding $300 \mu \mathrm{L}$ to a well. Two-hundred-eighty microliters of DPPH methanolic solution was added. The absorbance was recorded in a microplate reader (Bio Rad Model 680, Japan) at a wavelength of $515 \mathrm{~nm}$. Finally, at least three calibration curves were made by dissolving $2 \mathrm{mg}$ of Trolox in $10 \mathrm{~mL}$ methanol. The results were expressed as $\mu \mathrm{mol}$ of Trolox equivalent per gram ( $\mu \mathrm{mol} \mathrm{TE} / \mathrm{g})$.

\subsection{GC-MS analysis of VOCs}

Subsamples of chopped tomatoes ( $250 \mathrm{~g}$ ) were made into juice using a Turmix juice extractor Mod. TU04 (Waring Laboratory, Torrington, CT, USA) and filtered through a cloth. Two milliliters of juice was placed into a $4 \mathrm{~mL}$ amber vial with a septate lid containing $0.65 \mathrm{~g}$ of $\mathrm{NaCl}$ and stirred at $25^{\circ} \mathrm{C}$. Subsequently, a SPME fiber (65 mm DVB/CAR/PDMS) (Supelco, Inc., Bellefonte, PA, USA) was exposed for $27 \mathrm{~min}$ to the headspace of the sample to collect the VOCs (Servili et al., 2000). The VOC analysis was performed according to Servili et al. (2000) using a gas chromatograph (GC) Varian 3600 coupled to a mass spectrometry detector (MS) Varian Saturn 3 (Varian, Walnut Creek, CA, USA). The VOCs were separated in a DB-Wax fused-silica capillary column $(60 \mathrm{~m}$ $\times 0.25 \mathrm{~mm}, 0.25 \mu \mathrm{m}$ film thickness) (J \& W Scientific, Folsom, CA, USA). The separation started at $35^{\circ} \mathrm{C}$ for $8 \mathrm{~min}$, and then the oven temperature was gradually increased to $45^{\circ} \mathrm{C}, 150{ }^{\circ} \mathrm{C}$, $180^{\circ} \mathrm{C}, 210^{\circ} \mathrm{C}$ (maintained for $14.51 \mathrm{~min}$ ) at rates of $1.5^{\circ} \mathrm{C} / \mathrm{min}$, $3{ }^{\circ} \mathrm{C} / \mathrm{min}, 4{ }^{\circ} \mathrm{C} / \mathrm{min}$ and $4{ }^{\circ} \mathrm{C} / \mathrm{min}$, respectively. The injector was maintained at $250^{\circ} \mathrm{C}$, while the transfer line was fixed to $220^{\circ} \mathrm{C}$. GC-MS was performed using Saturn GC-MS Version 5.2 software (Varian, Walnut Creek, CA, USA). The VOCs were identified by comparing the mass spectra and the retention times with those of authentic reference compounds as well as comparing the mass spectra with those of the NIST-92 library. The concentration of VOCs was expressed as area.

\subsection{Experimental design and statistical data analysis}

Assays were performed four times per treatment using a completely randomized design. The data were analyzed by a balanced analysis of variance (ANOVA), and the means were separated by Tukey's test $(p=0.05)$. Data analysis was performed using Statistical Analysis System software version 9.0 (SAS Institute, 2002). 


\section{Results and discussion}

\subsection{Carotenoid composition}

The carotenoid content in the tested tomatoes (Figure 1) was similar to that previously reported (Hyman et al., 2004; Baranska et al., 2006; Gama et al., 2009; Ryan et al., 2009). Lycopene was the most abundant carotenoid $(46.4-167.6 \mu \mathrm{g} / \mathrm{g})$, followed by $\beta$-carotene $(6.6-16.2 \mu \mathrm{g} / \mathrm{g})$ and lutein $(1.5-3.1 \mu \mathrm{g} / \mathrm{g})$. Hyman et al. (2004) observed that the contents of lycopene and $\beta$-carotene in 11 tomato cultivars varied from 18 to $136 \mu \mathrm{g} / \mathrm{g}$ and from 2.4 to $6.7 \mu \mathrm{g} / \mathrm{g}$, respectively. Similar concentrations for these carotenoids $($ lycopene $=130-170 \mu \mathrm{g} / \mathrm{g} ; \beta$-carotene $=4.4-5.4 \mu \mathrm{g} / \mathrm{g}$ ) were reported by Baranska et al. (2006) and Ryan et al. (2009). The lutein content is not commonly studied in tomato; however, its content is low in tomatoes $(3.3 \mu \mathrm{g} / \mathrm{g})$ compared with the lycopene and $\beta$-carotene contents of tomatoes (Gama et al., 2009). The lycopene content represents more than $80 \%$ of the total carotenoid content in tomatoes, as observed in our study (Ligor et al., 2014; Ha et al., 2015). This carotenoid is responsible
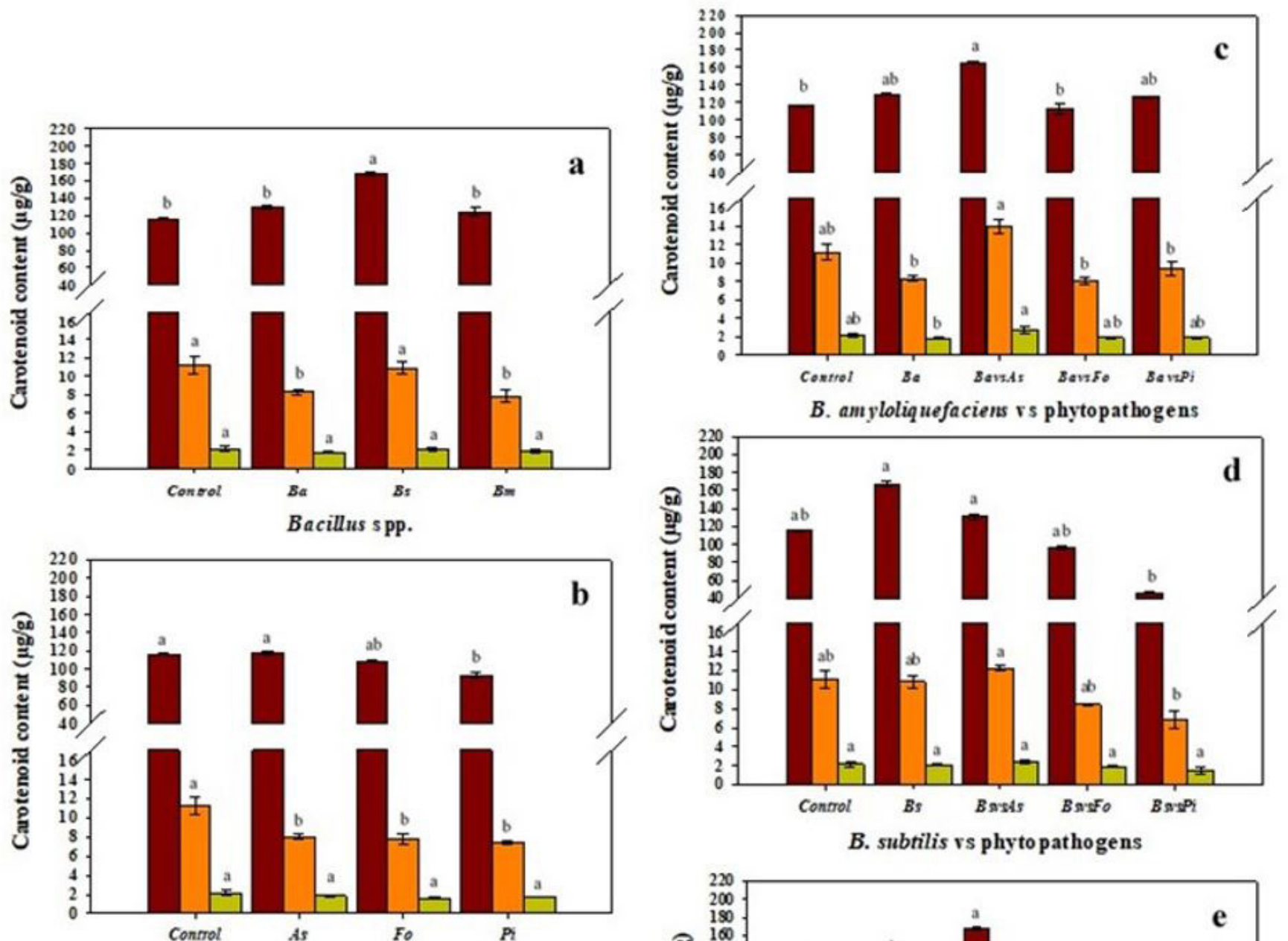

B. subtilis vs phyto pathogens

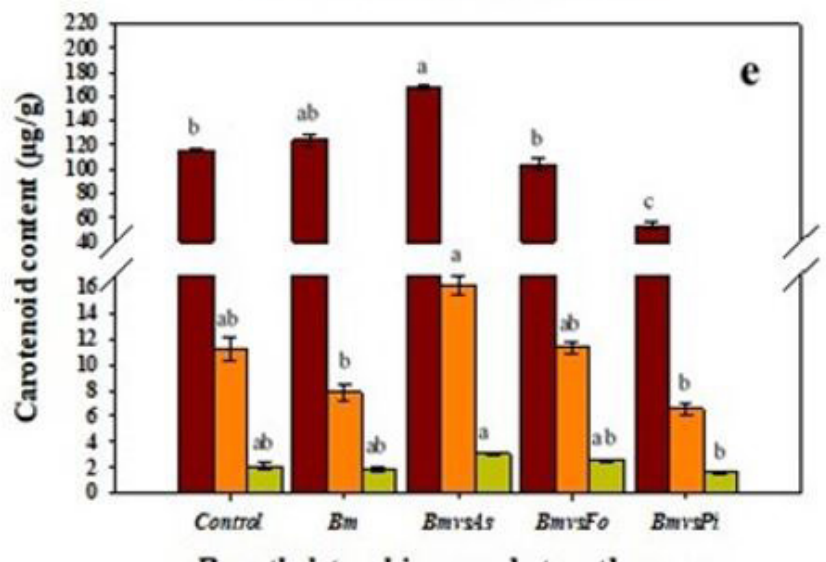

B. methylotroplicus vs phytopathogens

Figure 1. Carotenoid compound content of tomato fruits obtained from plants inoculated with (a) Bacillus species alone; (b) phytopathogens alone; and together (c) B. amyloliquefaciens vs phytopathogens; (d) B. subtilis vs phytopathogens; and (e) B. methylotrophicus vs phytopathogens. 
for the red color of tomato fruit and for the protective effect of tomato against prostate cancer, among other beneficial effects on human health (Hyman et al., 2004; Ordookhani et al., 2010; Ordookhani \& Zare, 2011; Ahn et al., 2019). Due to this, lycopene has been widely used as a functional ingredient for nutraceutical products or for functional food formulations (Pellicanò et al., 2020), especially because it is not produced by human body, therefore is usually obtained from fruits and vegetables such as tomato (Din et al., 2020).

The carotenoid content in tomato fruits increased with the inoculation of Bacillus strains, with the exception of the lutein content, which showed minor alterations in response to microorganism inoculation (Figure 1), probably due to carotenogenesis in tomato, which favors the accumulation of lycopene and $\beta$-carotene. The highest accumulation of carotenoids was obtained in fruits of plants inoculated with $B$. subtilis only (Figure 1). This can be attributed to the high root growth induced by these bacterial strains (Ruiz-Cisneros et al., 2019), which leads to better absorption of nutrients and, consequently, to the activation of several genetic and hormonal regulatory mechanisms, especially those associated with fruit ripening and carotenogenesis (Ordookhani et al., 2010; Ordookhani \& Zare 2011; Ligor et al., 2014; Pesaresi et al., 2014).

The fruits obtained from plants inoculated with phytopathogens only had significantly lower carotenoid accumulation than the plants under the Bacillus-only treatments and the control treatment. The fruits of the plants treated with $P$. infestans alone showed 20\% less lycopene than those obtained from the control plants (Figure 1).

Due to the stress to which the plants were subjected when inoculated with this phytopathogen, the biosynthesis of these bioactive compounds in the fruits may have been delayed by suppression of phytoene synthase activity, which contributes to carotenoid production in tomato fruit (Nisar et al., 2015).

The carotenoid content in fruits obtained from plants inoculated with Bacillus strains in combination with phytopathogens was variable (Figure 1). Those treatments in which the strains of Bacillus and A. solani interacted had a greater carotenoid accumulation with respect to that obtained with Bacillus-only treatments. This combination of microorganisms might cause alterations in the levels of phytohormones (i.e., abscisic acid, auxin and ethylene) that are involved in fruit ripening and carotenoid accumulation (Ligor et al., 2014; Su et al., 2015). Additionally, the increase in the contents of these phytochemicals could be due to the oxidation of carotenoids, which is the main cause of deterioration and is greater when cellular integrity is lost. The latter is the cause of the biotic stress induced by A. solani (Havaux, 2014). In the fruits obtained from treatments including interactions between the phytopathogen $P$. infestans and B. subtilis and B. methylotrophicus, the carotenoid content decreased significantly. This trend was observed in fruits obtained from plants inoculated with this phytopathogen alone, which shows the high virulence of $P$. infestans through alterations in plant physiological processes, such as photosynthesis, related to carotenoid accumulation (Nisar et al., 2015). However, when interacting with B. amyloliquefaciens, these parameters remained constant, which shows the putative biocontrol effect of this Bacillus strain via reducing the damage caused by this phytopathogen or activating the mechanisms of plant defense before the infection.

The carotenoid content in tomatoes has been determined to be affected by several factors, including genetic diversity, technification level, fruit ripening, and agronomic management; however, the effect of microorganism inoculation in soil on the phytochemical content has received little attention (RubioDiaz et al., 2010; Sgherri et al., 2007).

\subsection{Total Phenolic Content (TPC)}

Both Bacillus strains and phytopathogenic fungi alone and together caused increases in the TPC (Figure 2), which ranged from 0.42 to $0.90 \mathrm{mg} \mathrm{GAE} / \mathrm{g}$. These concentrations are similar to those reported for several tomato cultivars, including the cultivars 'Armada', 'Cheers', 'Amarelo, 'Batateiro/Redondo', 'Comprido' and 'Coração' (0.004-4.57 mg GAE/g FW) (Toor et al., 2006; Georgé et al., 2011; Barros et al., 2012). In our study, all fruits from plants treated with Bacillus strains and phytopathogens alone or together showed a significant increase in the TPC. Fruits harvested from plants inoculated with Bacillus strains contained 1.5 times more phenols than control fruits. The interaction of both microorganism types caused increases in phenols of up to 1.4- to 2.2-fold compared with those of control fruits. The interaction between the Bacillus strains and P. infestans caused the highest levels of phenols.

Plants treated with $F$. oxysporum in combination with B. amyloliquefaciens or B. methylotrophicus showed less fungal damage than other plants (data not shown), and their fruits showed a higher TPC than that from plants treated only with pathogens. This could be attributed to the activation of defense mechanisms in plants, especially systemic acquired resistance (SAR) induced by Bacillus strains, causing an increase in the TPC (Luna et al., 2012). Rhizosphere microorganisms can also activate some defense mechanisms in plants that involve the biosynthesis of phenolic compounds. Ardanov et al. (2011) demonstrated that the application of Bacillus to potato crops enhanced the activation of the defense system of plants against both biotic and abiotic stress agents. Thus, the inoculation of Bacillus or other nonpathogenic microorganisms might contribute to the synthesis of phenolic compounds mainly due to their plant growth activity (Toor et al., 2006). Pathogens can induce the biosynthesis of phenolic compounds by causing osmotic stress or increasing hormone activity in plants as a response to the disease caused by pathogens (Lola-Luz et al., 2014). The inoculation of plants with microorganisms causes the same effect on TPC as abiotic stress factors (i.e., low/high temperature, hydric stress, among others). Helyes et al. (2006) demonstrated that the content of flavonoids and phenylpropanoids in tomatoes was increased when the plants were subjected to thermal stress. However, the use of nonpathogenic microorganisms to increase the TPC has many advantages over abiotic stress because exert antagonistic activity towards pathogens and promote plant growth. Abiotic stress compromises the health of plants and the fruit yield (Havaux, 2014). Although phenolic compounds are an important part of the defense mechanisms of plants (Mahboubi et al., 2014), they also contribute to the quality of tomato fruits because they are involved in tomato color, taste, aroma and flavor. 

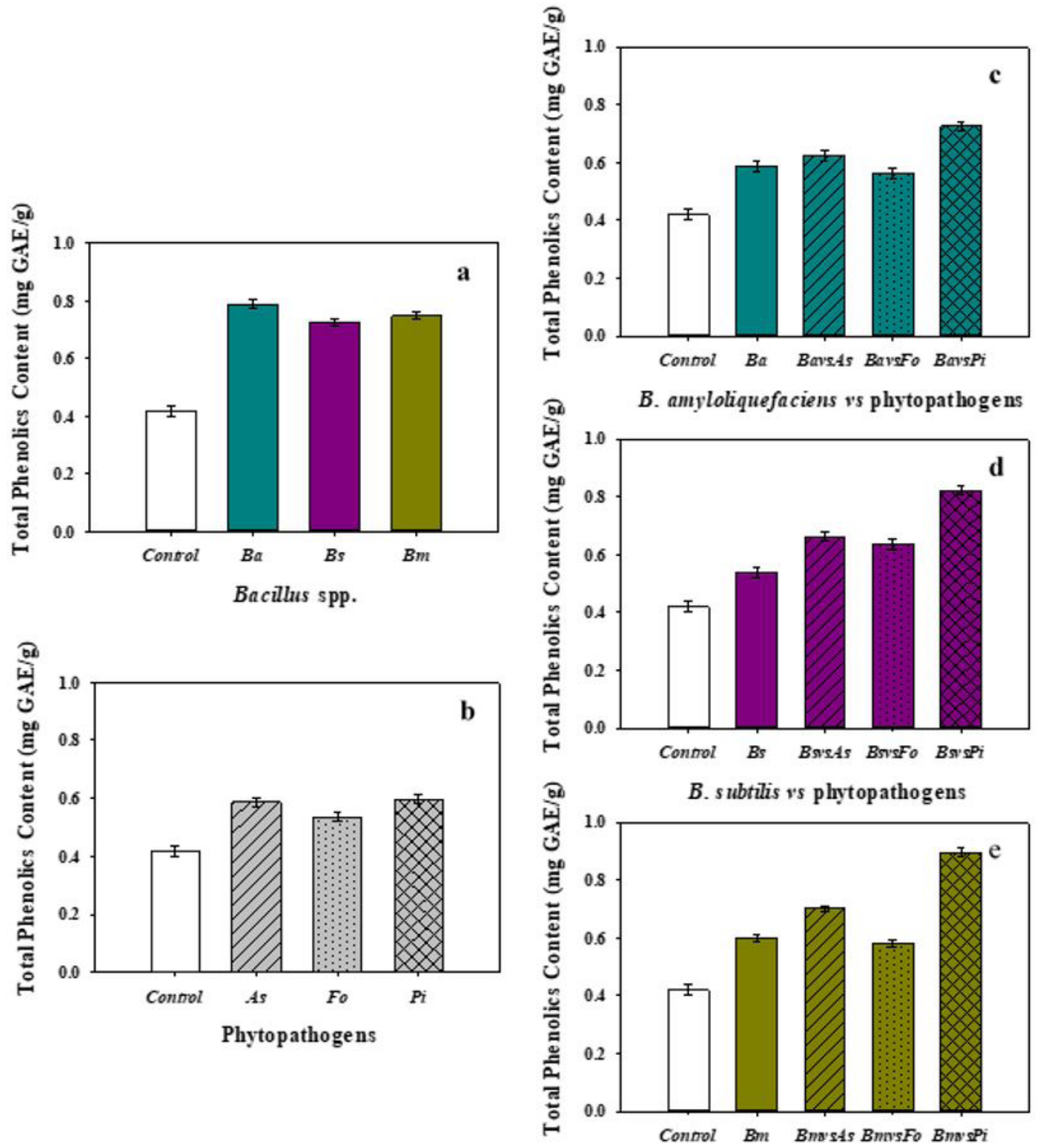

B. methylotrophicus is phytopathogens

Figure 2. Total phenolic content of tomato fruits obtained from plants inoculated with (a) Bacillus species alone; (b) phytopathogens alone; and together (c) B. amyloliquefaciens vs phytopathogens; (d) B. subtilis vs phytopathogens; and (e) B. methylotrophicus vs phytopathogens.

\subsection{Antioxidant capacity}

The antioxidant capacity of the tested extracts (6.5 to $19.9 \mu \mathrm{mol}$ $\mathrm{TE} / \mathrm{g}$ ) was similar to that reported in the literature (Figure 3). As observed in the TPC, the antioxidant capacity increased after inoculation of plants with both antagonistic and phytopathogenic microorganisms, alone or in combination. The antioxidant capacity of fruits from plants inoculated with Bacillus strains was 1.5-1.9-fold that of control fruit $(6.5 \mu \mathrm{mol} \mathrm{TE} / \mathrm{g})$. Fruits from plants treated with phytopathogens alone showed an antioxidant capacity up to 2.8 -fold higher than that of control fruit, with fruits from plants treated with $A$. solani showing the highest 


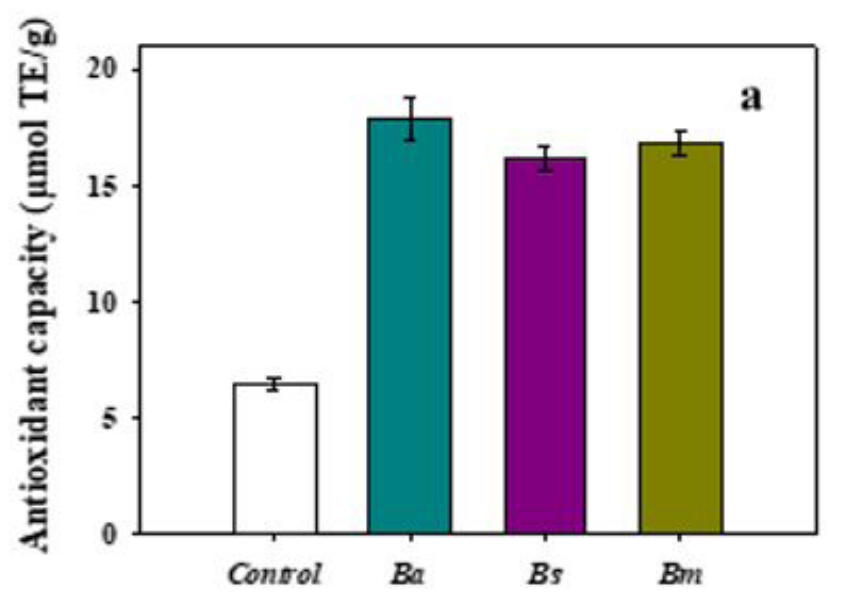

Bacillus spp.

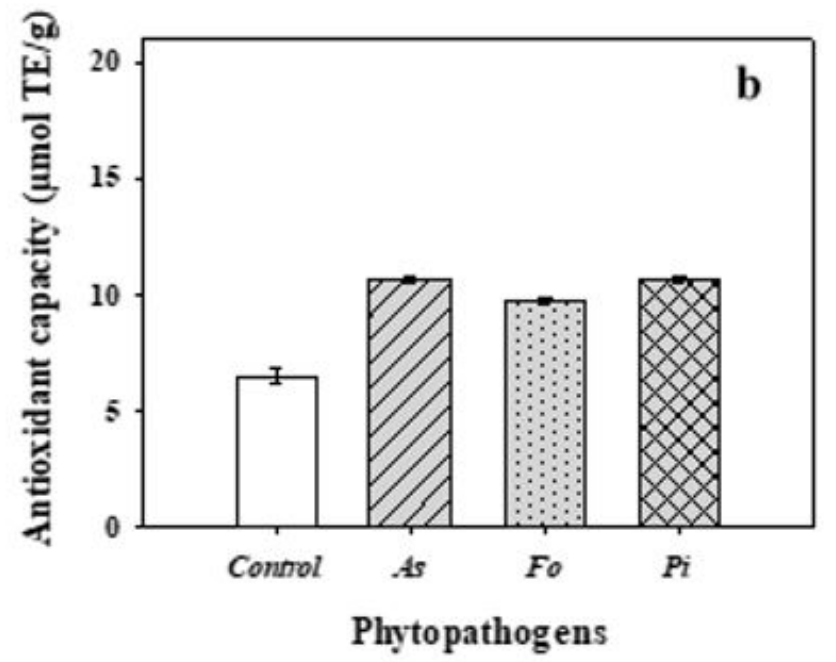

Fure 3. Antioxidant capacity of methanolic extracts of total phenolic compounds of tomato fruits obtained from plants inoculated with (a) Bacillus species alone; (b) phytopathogens alone; and together [(c) B. amyloliquefaciens vs phytopathogens; (d) B. subtilis vs phytopathogens; and (e) B. methylotrophicus vs phytopathogens].

antioxidant capacity $(17.9 \mu \mathrm{mol}$ TE/g; Figure 3) among these treatments. The inoculation of $B$. methylotrophicus vs $P$. infestans favored the highest antioxidant capacity $(19.9 \mu \mathrm{mol} \mathrm{TE} / \mathrm{g})$ among the interaction treatments.

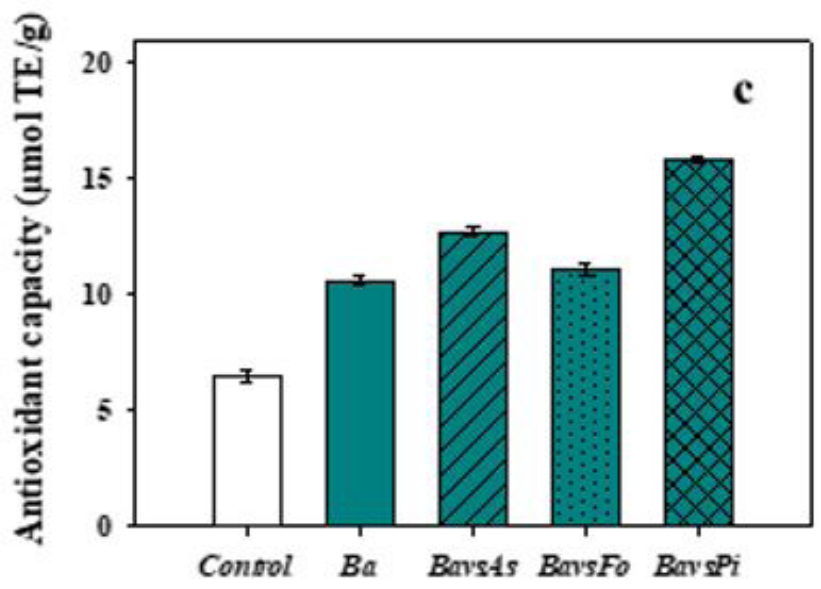

B. amyldiquefaciens ws phytop athogens
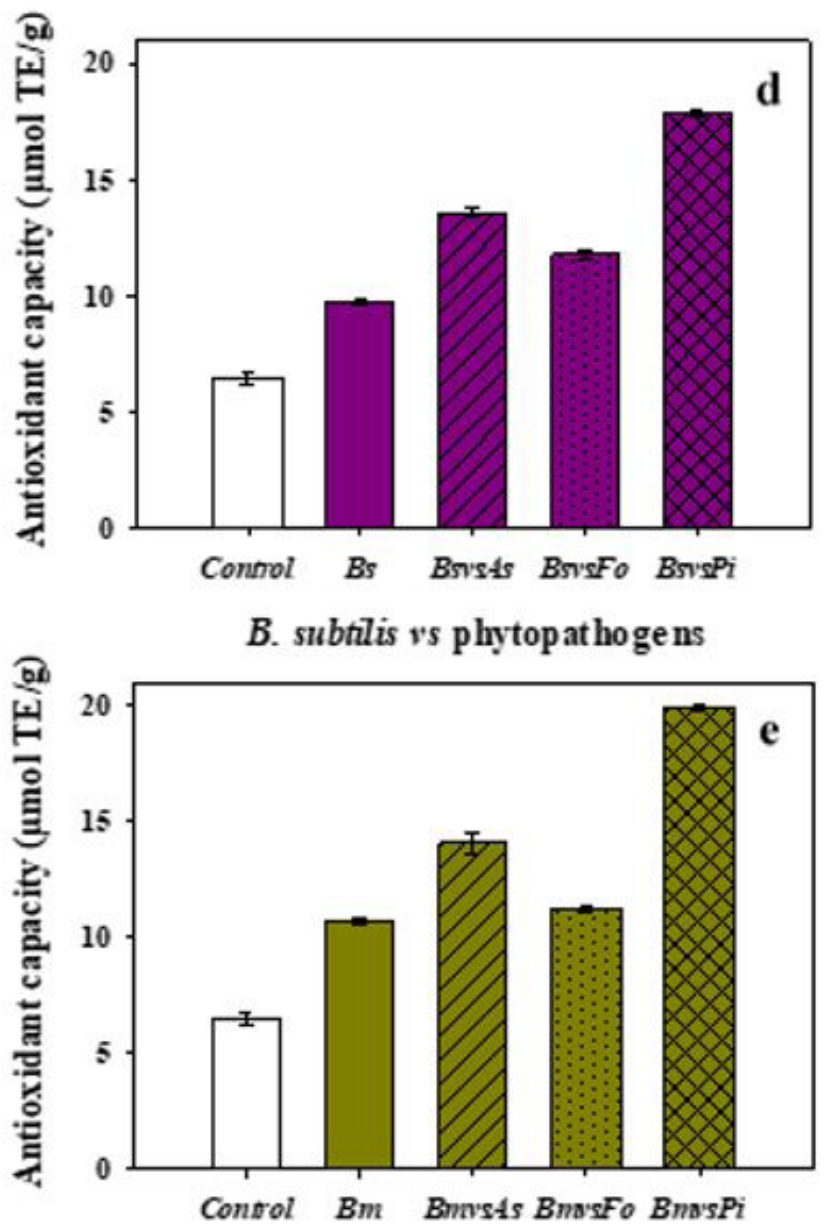

B. methylotrophicus vs phytop athogens 
compounds or phytohormones to reduce the resulting oxidative stress. Additionally, apart from antioxidant enzymes, there are nonenzymatic antioxidants, such as major cellular redox buffers, carotenoids, flavonoids, tocopherols, ascorbate, and glutathione, that also protect the plant from adverse effects induced by stress (Nadeem et al., 2014). This is indicative of the capacity of phenolic and carotenoid extracts to act as antioxidants, benefiting human health.

The regression analysis showed that the TPC and antioxidant capacity of fruits were highly correlated with each other $\left(R^{2}=\sim 97 \%\right)$.

\subsection{VOCs in tomato}

Tomatoes produce more than 400 volatile chemicals, of which only 15 or 20 VOCs are detected by human olfactory sensing (Dávila-Aviña et al., 2011). However, only 20-30 VOCs and their derivatives are commonly studied in tomato fruit (Servili et al., 2000; Dávila-Aviña et al., 2011; Rambla et al., 2013, 2015; Wang et al., 2016). In our study, 32 VOCs were identified in tested tomatoes according to their functional group, such as ketones, alcohols, aldehydes and others (Table 2).

These tomato VOCs are mainly formed from amino acids, fatty acids and carotenoids, giving distinctive odor descriptions such as fresh, green, fruity, and floral, among others. Six of these VOCs are involved in the aroma of fresh tomatoes (Figure 4), which in the right combination and concentration, give tomato fruits their characteristic fresh aroma. It is important to note that seven of the 32 VOCs identified in this study were synthetized either from carotenoids or phenolic acids (Table 2), showing the same trend as their precursors, indicating a correlation in the biosynthesis of both bioactive compounds and VOCs (Figure 4).

The composition of the VOC profile and other quality parameters depend on several factors, such as cultivar, ripening state, temperature, relative humidity, harvesting period, soil, and microorganisms associated with the crop (DávilaAviña et al., 2011; Rambla et al., 2013; Wang et al., 2016). In our study, six VOCs considered to impact tomato aroma were found, among which 2-hexenal showed higher concentrations

Table 2. Volatile compounds most often associated with tomato aroma, retention time, precursors and odor description obtained in tomato fruits from plants inoculated with Bacillus strains alone, phytopathogens alone and together, and control fruits.

\begin{tabular}{|c|c|c|c|c|}
\hline Group & Compound & $\mathrm{RT}(\mathrm{min})$ & Precursor & Odor description \\
\hline \multirow[t]{4}{*}{ Ketones } & 6-methyl-5-hepten-2-one & 34.3 & Carotenoids & Floral, fruity \\
\hline & 2-isobutyl-thiazole & 37.7 & Branched chain amino acids & Green, tomato plant \\
\hline & Pseudoionone & 60.9 & Carotenoids & Balsamic \\
\hline & $\beta$-ionone & 58.0 & Carotenoids & Floral, fruity \\
\hline \multirow[t]{13}{*}{ Alcohols } & 2-methylfuran & 7.6 & -- & -- \\
\hline & Ethanol & 10.7 & Fatty acids & Sweet \\
\hline & 2-methyl-propanol & 21.6 & Amino acids & -- \\
\hline & Butanol & 24.4 & Fatty acids & -- \\
\hline & 1-penten-3-ol & 25.2 & Fatty acids & Sweet, grassy, fruity \\
\hline & 2-methyl-1-butanol & 27.8 & Isoleucine & -- \\
\hline & 1-pentanol & 30.2 & Fatty acids & Balsamic \\
\hline & 1-hexanol & 35.3 & Fatty acids & Resin, flowers, green \\
\hline & 3-hexen-1-ol & 36.7 & Fatty acids & -- \\
\hline & 1-heptanol & 40.0 & Fatty acids & -- \\
\hline & 6-methyl-5-hepten-2-ol & 40.3 & Carotenoids & -- \\
\hline & 1-octanol & 40.7 & Fatty acids & -- \\
\hline & Linalool & 43.8 & Geranyl pyrophosphate & Citric, fruity, sweet \\
\hline \multirow[t]{12}{*}{ Aldehydes } & Isolvaleraldehyde & 9.4 & Isoleucine and leucine amino acids & -- \\
\hline & Valeraldehyde & 12.7 & Fatty acids & -- \\
\hline & Hexanal & 19.7 & Fatty acids & Green grass \\
\hline & Acetaldehyde & 20.6 & Alanine & -- \\
\hline & 2-hexenal & 27.9 & Fatty acids & Green \\
\hline & Octanal & 31.8 & -- & -- \\
\hline & Trans-2-heptenal & 33.6 & Fatty acids & Green \\
\hline & Nonanal & 37.1 & -- & -- \\
\hline & Furfural & 40.1 & -- & -- \\
\hline & Benzaldehyde & 42.8 & Lignin & -- \\
\hline & Phenylacetaldehyde & 47.6 & Phenylalanine & Floral, alcohol \\
\hline & Citral & 49.2 & Carotenoids & Citric \\
\hline \multirow[t]{3}{*}{ Others } & 4-Allylanisole & 48.8 & -- & Clove \\
\hline & Methyl salicylate & 52.7 & Lignin, phenolic acids & -- \\
\hline & Eugenol & 57.3 & Phenylalanine & -- \\
\hline
\end{tabular}



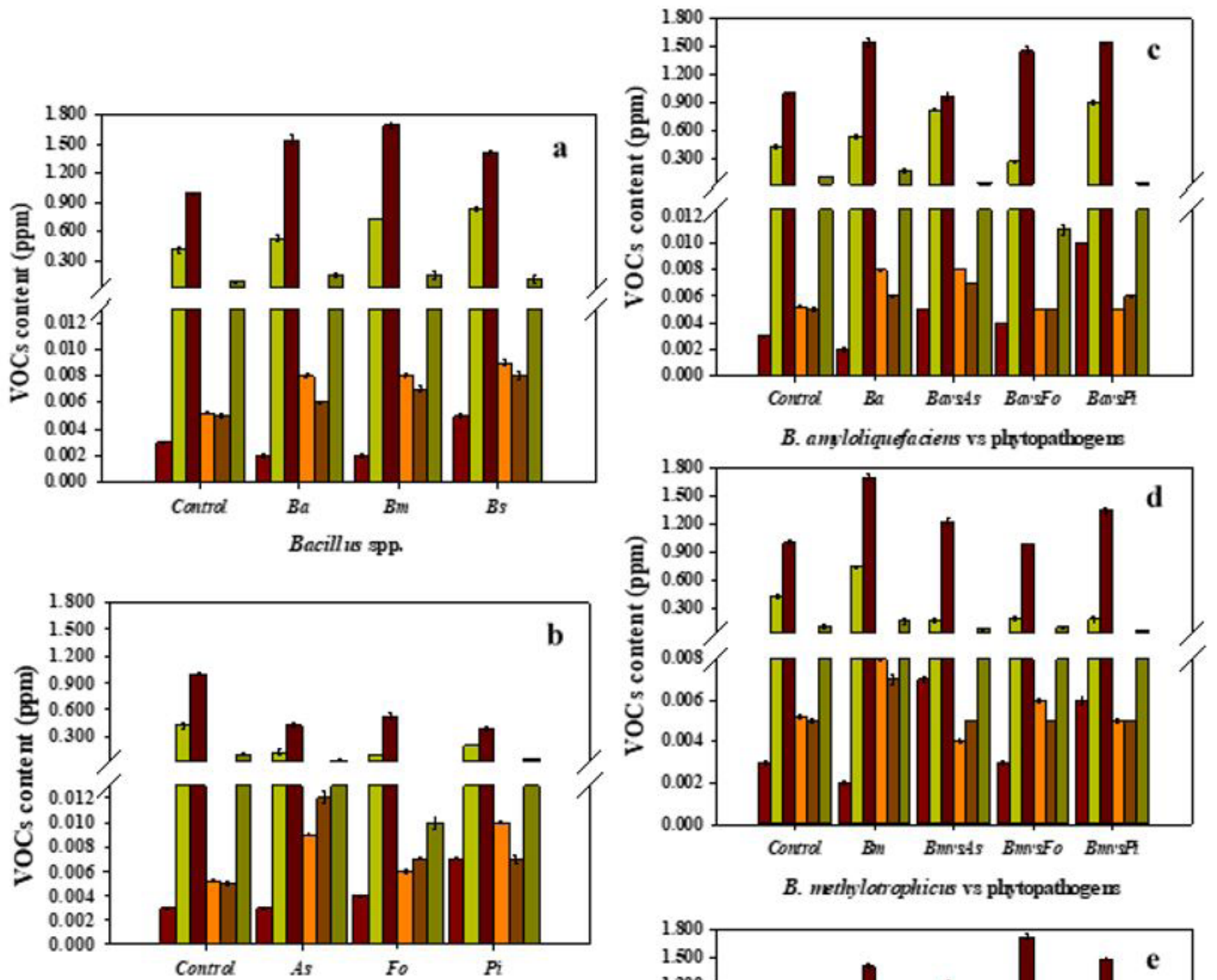

B. metlylorrophicis vs plytopathogens

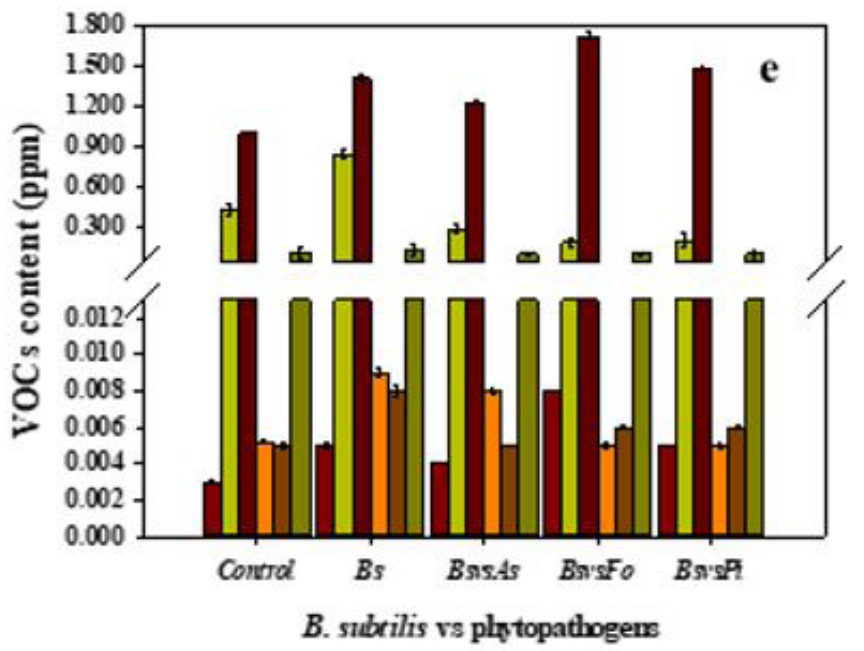

Figure 4. Content (ppm) of volatile organic compounds (VOCs) considered to impact tomato fruits obtained from plants inoculated with (a) Bacillus species alone; (b) phytopathogens alone; and together [(c) B. amyloliquefaciens vs phytopathogens; (d) B. subtilis vs phytopathogens; and (e) B. methylotrophicus vs phytopathogens].

in tomatoes harvested from plants inoculated with Bacillus strains than those from the rest of the treatments (Figure 4). This could be related to the intervention of these strains in plant defenses, since this compound is related to antimicrobial compounds (Silva et al., 2014). With the inoculation of Bacillus, the activation of defense mechanisms in plants, especially induced systemic resistance (ISR), could have been triggered, functioning like a vaccine to prepare the host for pathogen attack (Xue et al., 1998). Additionally, 2-hexenal is associated with a green odor, indicating that tomatoes from Bacillus treatments 
had a greener aroma than those obtained from phytopathogen treatments. In contrast, when phytopathogen inoculation was carried out, this compound decreased in tomatoes, which indicates that tomato fruits obtained from plants inoculated with phytopathogens had an accelerated ripening process, since this VOC is related to a green odor. The content of this VOC in tomato fruits obtained from plants inoculated with Bacillus and phytopathogens showed the same trend as the bioactive compounds. These results indicate that antagonistic Bacillus strains trigger plant defenses and protect the plant from attack by phytopathogens by the production of antimicrobial compounds (Silva et al., 2014).

6-methyl-5-hepten-2-one was another compound with a similar behavior (Figure 4). The precursors of this compound are carotenoids (Table 2). This explains its content in tomatoes harvested from plants inoculated with Bacillus strains, where a similar trend was observed for the carotenoid content in the same treatments (Figure 1).

Both events can be attributed to plant stress induced by microorganisms. However, this effect was higher in tomatoes from plants inoculated with phytopathogens, which accelerated ripening. On the other hand, methyl salicylate's precursor is salicylic acid, a compound associated with SAR as a plant defense response (Rivas-San Vicente \& Plasencia, 2011). This VOC was found in higher amounts in the fruits harvested from plants inoculated with Bacillus strains, so it could be inferred that these strains activated SAR in plants, contrary to what was observed with phytopathogens. Wang et al. (2016) reported that salicylic acid is methylated to methyl salicylate through salicylic acid methyl transferase, and the expression of this enzyme decreases as tomatoes ripen. Fruits harvested at the red ripening state from plants inoculated with phytopathogens ripened faster, even when all fruits were harvested in the same state, and were also the least firm (Ruiz-Cisneros et al., 2019).

\section{Conclusions}

Bacillus strains contributed to the increase in bioactive compounds, mainly carotenoids, and to a lower TPC and antioxidant capacity. Additionally, the quality of tomatoes was improved based on their VOC profile, with a fresh (green) tomato aroma. These results indicate that these bacterial strains are a promising alternative to be used as fruit quality enhancers in horticultural crops. Although the relationship between the production of VOCs, carotenoids, phenolic compounds and their antioxidant capacity during tomato ripening is not fully elucidated, the results of this study could be used for future analysis and research.

\section{References}

Ahn, S. I., Chogsom, C., Lee, Y. K., Kwak, H. S., \& Chang, Y. H. (2019). Optimization of the conditions for producing water-in-oil-in-water microemulsions and spray-dried microcapsule of tomato extract powder. Food Science and Technology, 39(Suppl. 1), 202-210. http:// dx.doi.org/10.1590/fst.42017.

Ardanov, P., Ovcharenko, L., Zaets, I., Kozorovska, N., \& Pirttilä, A. M. (2011). Endophytic bacteria enhancing growth and disease resistance of potato (Solanum tuberosum L.). Biological Control, 56(1), 43-49. http://dx.doi.org/10.1016/j.biocontrol.2010.09.014.
Baranska, M., Schütze, W., \& Schulz, H. (2006). Determination of lycopene and $\beta$-carotene content in tomato fruits and related products: comparison of FT-Raman, ATR-IR, and NIR spectroscopy. Analytical Chemistry, 78(24), 8456-8461. http://dx.doi.org/10.1021/ ac061220j. PMid:17165839.

Barros, L., Dueñas, M., Pinela, J., Carvalho, A. M., Buelga, C. S., \& Ferreira, I. C. (2012). Characterization and quantification of phenolic compounds in four tomato (Lycopersicon esculentum L.) farmers' varieties in northeastern Portugal homegardens. Plant Foods for Human Nutrition, 67(3), 229-234. http://dx.doi.org/10.1007/ s11130-012-0307-z. PMid:22922837.

Beneduzi, A., Ambrosini, A., \& Passaglia, L. M. (2012). Plant growthpromoting rhizobacteria (PGPR): their potential as antagonists and biocontrol agents. Genetics and Molecular Biology, 35(4), 1044-1051. http://dx.doi.org/10.1590/S1415-47572012000600020. PMid:23411488.

Brand-Williams, W., Cuvelier, M. E., \& Berset, C. (1995). Use of a free radical method to evaluate antioxidant activity. LebensmittelWissenschaft + Technologie, 28(1), 25. http://dx.doi.org/10.1016/ S0023-6438(95)80008-5.

Cervantes-Paz, B., Yahia, E. M., Ornelas-Paz, J. D. J., Gardea-Béjar, A. A., Ibarra-Junquera, V., \& Pérez-Martínez, J. D. (2012). Effect of heat processing on the profile of pigments and antioxidant capacity of green and red jalapeño peppers. Journal of Agricultural and Food Chemistry, 60(43), 10822-10833. http://dx.doi.org/10.1021/ jf303091u. PMid:23050605.

Dávila-Aviña, J. E. D. J., González-Aguilar, G. A., Ayala-Zavala, J. F., Sepúlveda, D. R., \& Olivas, G. I. (2011). Compuestos volátiles responsables del sabor del tomate. Revista Fitotecnia Mexicana, 34(2), 133-143. http://dx.doi.org/10.35196/rfm.2011.2.133.

Din, A., Amir, R. M., Ameer, K., Ahmad, A., Nadeem, M., Chughtai, M. F. J., Khaliq, A., Ahsan, S., Khan, M. I., Riaz, A., \& Kausar, R. (2020). Assessment of quality attributes of tomato sauce supplemented with moringa root. Food Science and Technology, 40(4), 1014-1020. http:// dx.doi.org/10.1590/fst.26719.

El Hadi, M. A. M., Zhang, F. J., Wu, F. F., Zhou, C. H., \& Tao, J. (2013). Advances in fruit aroma volatile research. Molecules, 18(7), 82008229. http://dx.doi.org/10.3390/molecules18078200. PMid:23852166.

Gama, J. J. T., Tadiotti, A. C., \& Sylos, C. M. (2009). Comparison of carotenoid content in tomato, tomato pulp and ketchup by liquid chromatography. Alimentos e Nutrição, 17(4), 353-358. Retrieved from https://pdfs.semanticscholar.org/2ffd/31118f18d5df299479c 20f9a7075d320aa78.pdf

Georgé, S., Tourniaire, F., Gautier, H., Goupy, P., Rock, E., \& Caris-Veyrat, C. (2011). Changes in the contents of carotenoids, phenolic compounds and vitamin $\mathrm{C}$ during technical processing and lyophilisation of red and yellow tomatoes. Food Chemistry, 124(4), 1603-1611. http:// dx.doi.org/10.1016/j.foodchem.2010.08.024.

Ha, T. V. A., Kim, S., Choi, Y., Kwak, H. S., Lee, S. J., Wen, J., Oey, I., \& Ko, S. (2015). Antioxidant activity and bioaccessibility of size-different nanoemulsions for lycopene-enriched tomato extract. Food Chemistry, 178, 115-121. http://dx.doi.org/10.1016/j.foodchem.2015.01.048. PMid:25704691.

Havaux, M. (2014). Carotenoid oxidation products as stress signals in plants. The Plant Journal, 79(4), 597-606. http://dx.doi.org/10.1111/ tpj.12386. PMid:24267746.

Helyes, L. D. J. P. Z., Dimény, J., Pék, Z., \& Lugasi, A. (2006). Effect of maturity stage on content, color and quality of tomato (Lycopersicon lycopersicum (L.) Karsten) fruit. International Journal of Horticultural Science, Budapest, 12(1), 41-44. http://dx.doi.org/10.31421/ IJHS/12/1/621. 
Hyman, J. R., Gaus, J., \& Foolad, M. R. (2004). A rapid and accurate method for estimating tomato lycopene content by measuring chromaticity values of fruit puree. Journal of the American Society for Horticultural Science, 129(5), 717-723. http://dx.doi.org/10.21273/ JASHS.129.5.0717.

Kubalt, K. (2016). The role of phenolic compounds in plant resistance. Biotechnology and Food Sciences, 80(2), 97-108. Retrieved from http://212.51.210.149/bitstream/handle/11652/1613/Role_phenolic_ compounds_Kulbat_2016.pdf?sequence=1\&isAllowed=y

Ligor, M., Kováčová, J., Gadzała-Kopciuch, R. M., Studzińska, S., Bocian, S., Lehotay, J., \& Buszewski, B. (2014). Study of RP HPLC retention behaviors in analysis of carotenoids. Chromatographia, 77(15-16), 10471057. http://dx.doi.org/10.1007/s10337-014-2657-1. PMid:25089049.

Lola-Luz, T., Hennequart, F., \& Gaffney, M. (2014). Effect on yield, total phenolic, total flavonoid and total isothiocyanate content of two broccoli cultivars (Brassica oleraceae var italica) following the application of a commercial brown seaweed extract (Ascophyllum nodosum). Agricultural and Food Science, 23(1), 28-37. http://dx.doi. org/10.23986/afsci.8832.

López-Vidal, O., Escalona-Buendía, H., Pelayo-Zaldívar, C., Cruz-Salazar, J., Villa-Hernández, J. M., Rivera-Cabrera, F., Villegas-Torres, O., Alia-Tejacal, I., Pérez-Flores, L. J., \& Díaz de León-Sánchez, F. (2014). Carotenoides, capacidad antioxidante y compuestos volátiles del aroma durante la maduración de jitomate. Phyton, 83(1), 185-192. Retrieved from http://www.scielo.org.ar/pdf/phyton/v83n1/v83n1a24.pdf

Luna, E., Bruce, T. J., Roberts, M. R., Flors, V., \& Ton, J. (2012). Nextgeneration systemic acquired resistance. Plant Physiology, 158(2), 844-853. http://dx.doi.org/10.1104/pp.111.187468. PMid:22147520.

Mahboubi, A., Kamalinejad, M., Ayatollahi, A. M., \& Babaeian, M. (2014). Total phenolic content and antibacterial activity of five plants of Labiatae against four foodborne and some other bacteria. Iranian Journal of Pharmaceutical Research: IJPR, 13(2), 559-566. PMid:25237351.

Mukherjee, T., Bose, S., \& Mukhopadhyay, S. K. (2017). Antioxidant properties of the carotenoid extracts of three Deinococcus-Thermus phylum bacteria, Meiothermus sp. strains RP and TP and Thermus sp. strain YY from Paniphala hot spring, India. Nutrire, 42(1), 7. http://dx.doi.org/10.1186/s41110-017-0032-3.

Nadeem, S. M., Ahmad, M., Zahir, Z. A., Javaid, A., \& Ashraf, M. (2014). The role of mycorrhizae and plant growth promoting rhizobacteria (PGPR) in improving crop productivity under stressful environments. Biotechnology Advances, 32(2), 429-448. http://dx.doi.org/10.1016/j. biotechadv.2013.12.005. PMid:24380797.

Nisar, N., Li, L., Lu, S., Khin, N. C., \& Pogson, B. J. (2015). Carotenoid metabolism in plants. Molecular Plant, 8(1), 68-82. http://dx.doi. org/10.1016/j.molp.2014.12.007. PMid:25578273.

Ordookhani, K., \& Zare, M. (2011). Effect of Pseudomonas, Azotobacter and arbuscular mycorrhiza fungi on lycopene, antioxidant activity and total soluble solid in tomato (Lycopersicon esculentum F1 Hybrid, Delba). Advances in Environmental Biology, 5(6), 1290-1294. Retrieved from http://www.aensiweb.com/old/aeb/2011/1290-1294.pdf

Ordookhani, K., Khavazi, K., Moezzi, A., \& Rejali, F. (2010). Influence of PGPR and AMF on antioxidant activity, lycopene and potassium contents in tomato. African Journal of Agricultural Research, 5(10), 1108-1116. http://dx.doi.org/10.5897/AJAR09.183.

Parewa, H. P., Yadav, J., Rakshit, A., Meena, V. S., \& Karthikeyan, N. (2014). Plant growth promoting rhizobacteria enhance growth and nutrient uptake of crops. Agriculture for Sustainable Development, 2(2), 101-116. Retrieved from http://sustainableagriculture.in/wpcontent/uploads/2017/09/4.ASD177HANUMANPRASADPAREWAJ. YADAV1A.RAKSHIT1V.S.MEENA2ANDN.KARTHIKEYAN3_1_.pdf
Pellicanò, T. M., Sicari, V., Loizzo, M. R., Leporini, M., Falco, T., \& Poiana, M. (2020). Optimization the supercritical fluid extraction process of bioactive compounds from processed tomato skin by-products. Food Science and Technology, 40(3), 692-697.http://dx.doi.org/10.1590/fst.16619.

Pesaresi, P., Mizzotti, C., Colombo, M., \& Masiero, S. (2014). Genetic regulation and structural changes during tomato fruit development and ripening. Frontiers of Plant Science, 5, 124. http://dx.doi. org/10.3389/fpls.2014.00124. PMid:24795731.

Rambla, J. L., Alfaro, C., Medina, A., Zarzo, M., Primo, J., \& Granell, A. (2015). Tomato fruit volatile profiles are highly dependent on sample processing and capturing methods. Metabolomics, 11(6), 1708-1720. http://dx.doi.org/10.1007/s11306-015-0824-5.

Rambla, J. L., Tikunov, Y. M., Monforte, A. J., Bovy, A. G., \& Granell, A. (2013). The expanded tomato fruit volatile landscape. Journal of Experimental Botany, 65(16), 4613-4623. http://dx.doi.org/10.1093/ jxb/eru128. PMid:24692651.

Rivas-San Vicente, M., \& Plasencia, J. (2011). Salicylic acid beyond defense: its role in plant growth and development. Journal of Experimental Botany, 62(10), 3321-3338. http://dx.doi.org/10.1093/ jxb/err031. PMid:21357767.

Rubio-Diaz, D. E., Nardo, T., Santos, A., Jesús, S., Francis, D., \& RodriguezSaona, L. E. (2010). Profiling of nutritionally important carotenoids from genetically-diverse tomatoes by infrared spectroscopy. Food Chemistry, 120(1), 282-289. http://dx.doi.org/10.1016/j. foodchem.2009.09.060.

Ruiz-Cisneros, M. F., Ornelas-Paz, J. J., Olivas-Orozco, G. I., AcostaMuñiz, C. H., Sepúlveda-Ahumada, D. R., Zamudio-Flores, P. B., Berlanga-Reyes, D. I., Salas-Marina, M. A., Cambero-Campos, O. J., \& Rios-Velasco, C. (2019). Efecto de cepas de Bacillus solas y en interacción con hongos fitopatógenos sobre el crecimiento vegetal y calidad del fruto de jitomate. Biociencias, 6, e541. http://dx.doi. org/10.15741/revbio.06.e541.

Ryan, L., Aherne, S. A., Daly, T., Jiwan, M. A., \& O’Brien, N. M. (2009). Carotenoid content of raw tomato and processed tomato-based products. Proceedings of the Nutrition Society, 68, E108. http:// dx.doi.org/10.1017/S0029665109990644.

SAS Institute. (2002). Statistical Analysis System software version 9.0. Cary.

Servili, M., Selvaggini, R., Taticchi, A., Begliomini, A. L., \& Montedoro, G. (2000). Relationships between the volatile compounds evaluated by solid phase microextraction and the thermal treatment of tomato juice: optimization of the blanching parameters. Food Chemistry, 71(3), 407-415. http://dx.doi.org/10.1016/S0308-8146(00)00187-4.

Sgherri, C., Navari-Izzo, F., Pardossi, A., Soressi, G. P., \& Izzo, R. (2007). The influence of diluted seawater and ripening stage on the content of antioxidants in fruits of different tomato genotypes. Journal of Agricultural and Food Chemistry, 55(6), 2452-2458. http://dx.doi. org/10.1021/jf0634451. PMid:17323974.

Silva, L. R., Azevedo, J., Pereira, M. J., Carro, L., Velazquez, E., Peix, A., Valentâo, P., \& Andrade, P. B. (2014). Inoculation of the nonlegume Capsicum annuum L. with Rhizobium Strains. 2. Changes in sterols, triterpenes, fatty acids, and volatile compounds. Journal of Agricultural and Food Chemistry, 62(3), 565-573. http://dx.doi.org/10.1021/jf4046655. PMid:24405510.

Spanos, G. A., Wrolstad, R. E., \& Heatherbell, D. A. (1990). Influence of processing and storage on the phenolic composition of apple juice. Journal of Agricultural and Food Chemistry, 38(7), 1572-1579. http://dx.doi.org/10.1021/jf00097a031.

Su, L., Diretto, G., Purgatto, E., Danoun, S., Zouine, M., Li, Z., Roustan, J. P., Bouzayen, M., Giuliano, G., \& Chervin, C. (2015). Carotenoid accumulation during tomato fruit ripening is modulated by the auxin-ethylene balance. BMC Plant Biology, 15(1), 114. http://dx.doi. org/10.1186/s12870-015-0495-4. PMid:25953041. 
Toor, R. K., Savage, G. P., \& Heeb, A. (2006). Influence of different types of fertilisers on the major antioxidant components of tomatoes. Journal of Food Composition and Analysis, 19(1), 20-27. http:// dx.doi.org/10.1016/j.jfca.2005.03.003.

Vieira, D. A. P., Caliari, M., Souza, E. R. B., \& Soares-Junior, M. S. (2019). Mechanical resistance, biometric and physicochemical characteristics of tomato cultivars for industrial processing. Food Science and Technology, 39(Suppl. 2), 363-370. http://dx.doi. org/10.1590/fst.32417.

Vogel, J. T., Tieman, D. M., Sims, C. A., Odabasi, A. Z., Clark, D. G., \& Klee, H. J. (2010). Carotenoid content impacts flavor acceptability in tomato (Solanum lycopersicum). Journal of the Science of Food and Agriculture, 90(13), 2233-2240. http://dx.doi.org/10.1002/jsfa.4076. PMid:20661902.
Wang, L., Baldwin, E. A., \& Bai, J. (2016). Recent advance in aromatic volatile research in tomato fruit: The metabolisms and regulations. Food and Bioprocess Technology, 9(2), 203-216. http://dx.doi. org/10.1007/s11947-015-1638-1.

Xue, L., Charest, P. M., \& Jabaji-Hare, S. H. (1998). Systemic induction of peroxidases, $1,3-\beta$-glucanases, chitinases, and resistance in bean plants by binucleate Rhizoctonia Species. Phytopathology, 88(4), 359-365. http://dx.doi.org/10.1094/PHYTO.1998.88.4.359. PMid:18944960.

Zanfini, A., Corbini, G., La Rosa, C., \& Dreassi, E. (2010). Antioxidant activity of tomato lipophilic extracts and interactions between carotenoids and $\alpha$-tocopherol in synthetic mixtures. LebensmittelWissenschaft + Technologie, 43(1), 67-72. http://dx.doi.org/10.1016/j. lwt.2009.06.011. 